\title{
Metadata Application Profile for Agricultural Learning Resources
}

\author{
Hilke Stuempel $^{1}$, Gauri Salokhe ${ }^{1}$, Anne Aubert ${ }^{1}$, Johannes Keizer ${ }^{1}$, Andrew \\ Nadeau $^{1}$, Stephen Katz ${ }^{1}$, Stephen Rudgard ${ }^{1}$ \\ ${ }^{1}$ Food and Agriculture Organization of the United Nations, Knowledge Exchange \& \\ Capacity Building Division (KCE), Viale delle Terme di Caracalla, 00153 Rome, Italy \\ \{Hilke.Stuempel, Gauri.Salokhe, Anne.Aubert, Johannes.Keizer, Andrew.Nadeau, \\ Stephen.Katz, Stephen.Rudgard\}@fao.org
}

\begin{abstract}
Capacity and institution building is a core function of the Food and Agricultural Organization of the United Nations (FAO). FAO has recently started the "Capacity and Institution Building Portal" to provide structured access to information on FAO's capacity and institution building services and learning resources. To ensure that the Portal can be searched by users and to enable interoperability with other recognized educational repositories, an Application Profile (AP) was created conforming to available and commonly used standards, to describe agricultural learning resources. This article presents the AP, provides an example of an FAO learning resource described and displayed using FAO Learning Resource AP, and presents the lessons learned.
\end{abstract}

Keywords: metadata, information management, content management, learning object repositories, learning objects, agriculture

\section{Background - Capacity and Institution Building Portal}

The United Nations General Assembly (A/RES/59/250) recognizes the crucial role of capacity building for achieving the Millennium Development Goals and calls upon the United Nations organizations to increase their support to developing countries' own efforts [1]. Capacity and institution building is a core function of the Food and Agriculture Organization (FAO) of the United Nations. In order to provide structured access to FAO's agricultural learning resources and capacity and institution building services, the "Capacity and Institution Building Portal" (hereafter referred to as 'the Portal') project was started in 2006.

The Portal will provide direct access to learning resources, such as training materials, guidelines, tool kits, available in any media, which are usable in or prepared in support of a learning process by which individuals, groups and organizations can enhance their skills, and develop associated knowledge, attitudes and values, to improve their performance and solve problems in order to achieve their objectives. It will also facilitate access by external users, as well as FAO staff, to the Organization's learning resources and services, thus enhancing member countries' capacities. 
To ensure that the Portal can be searched by users and to enable interoperability with other Learning Object Repositories (LOR), one of the core activities of this project was to design an Application Profile (AP) which adheres to standard nomenclature to describe agricultural learning resources. An Application Profile is defined as a schema which consists of data elements drawn from one or more namespaces, combined together and optimized for a particular local application.

In the following sections the paper establishes the need for metadata to describe learning resources, analyses existing standards and details the requirements for an AP. Finally, it illustrates the elements of FAO’s Agricultural Learning Resources AP.

\section{Metadata for Describing Learning Resources}

Metadata for learning resources are important to facilitate search, access, use and reuse of learning objects, for instance, by learners or instructors. The learning objects or the relating metadata records are often stored in LORs. Different LORs address different needs and, therefore, have different metadata schemas. To enable interoperability and easy sharing of resources between these repositories (and to facilitate federated search or metadata harvesting), the use of common standards and specifications becomes essential [2]. This section describes some of the common standards used in educational settings.

The Institute of Electrical and Electronics Engineers (IEEE) provides an internationally-recognized open standard for the description of learning resources. The so called IEEE 1484.12.1-2002 Learning Object Metadata Standard (LOM) ${ }^{1}$ is based on early specifications contributed by the IMS Project ${ }^{2}$ and by ARIADNE ${ }^{3}$ [3]. The Standard comprises a hierarchy of elements. At the first level, there are nine categories: general, lifecycle, meta-metadata, technical, educational, rights, relation, annotation and classification. Each of these categories contains several sub-categories and thus, in total, LOM provides 76 data elements. The standard is widely used in educational context and applied in several LORs. It forms the basis for many recommendations and metadata APs, such as, ARIADNE, CanCore ${ }^{4}$, UK LOM Core ${ }^{5}$, SCORM $^{6}$ and IMS Learning Design ${ }^{7}$. It is also used for the Agricultural LOR of the Consultative Group on International Agricultural Research (CGIAR).

The International Standards Organization (ISO) sub-committee on "Information Technology for Learning, Education and Training" (ISO/IEC JTC1 SC36) started to develop a metadata standard for learning resources [4]. The group focuses on existing standards and conducted a survey on the use of LOM [5].

\footnotetext{
${ }^{1}$ Institute of Electrical and Electronics Engineers: http://www.ieee.org

2 IMS Global Learning Consortium: http://www.imsglobal.org

${ }^{3}$ ARIADNE Foundation for the European Knowledge Pool: http://www.ariadne-eu.org

${ }^{4}$ CanCore Learning Resource Metadata Initiative: http://www.cancore.ca/en/

${ }^{5}$ United Kingdom LOM Core: http://www.cetis.ac.uk/profiles/uklomcore

${ }^{6}$ Sharable Content Object Reference Model (SCORM): http://www.adlnet.gov/scorm/

${ }^{7}$ IMS Global Learning Consortium:

Learning Resource Meta-data Specification: http://www.imsglobal.org/metadata/index.html / Learning Design Specification: http://www.imsglobal.org/learningdesign/
} 
Furthermore, the Education Working Group of the Dublin Core Metadata Initiative $^{8}$ developed Dublin Core (DC) terms to describe educational resources. They proposed a small number of LOM elements to enhance a DC record ${ }^{9}$. Several learning repositories, such as the Gateway to 21st Century Skills (GEM) ${ }^{10}$ and the Education Network Australia (EdNA) ${ }^{11}$, follow the recommendations provided by the DC Education Working Group.

\section{Considerations for the Application Profile for FAO's Agricultural Learning Resources}

An important consideration when developing the AP for FAO's agricultural learning resources was the conformance with existing standards so as to assure that metadata records can be shared with other educational repositories, especially with those providing agricultural learning resources.

A study recently conducted by the Agricultural University of Athens [6] indicates that of the 59 repositories analyzed, 54\% use LOM or compatible APs based on IMS and Cancore, and 22\% use DC. Although the tendency of most LORs is to use the LOM set, FAO decided to base its standard on Dublin Core, for the reasons listed below.

A considerable amount of FAO's resources which have been identified as learning resources already have a metadata record in one of FAO's repositories. These resources are currently described using the AGRIS AP, which is based on DC and the Agricultural Metadata Element Set (AgMES) ${ }^{12}$. This specification is widely used by FAO and its partner organizations. Most of the elements in this standard overlap with metadata necessary to describe learning resources such as title, publisher, date of publication, language, subject etc. To be able to reuse these records would imply immense cost-savings, so an AP based on DC and AgMES was considered the optimal solution.

Additionally, because the AP would be promoted to FAO's member countries, who wish to establish similar LORs, it was important to ensure that it would be easy to use and implement. Thus, it was also important to identify a balanced number of data elements to keep the metadata creation effort manageable and to ensure a high return on investment. An AP which uses the complete set of 76 LOM elements was, therefore, not practical. A survey on the usage of LOM shows, that in practice most communities use only parts of the complete set [5]. Moreover, there is an overlap between the common elements in LOM and Dublin Core.

Given the above circumstances, the most cost effective solution in the case of FAO resources was to set up an exchange profile with Dublin Core, AgMES and LOM elements.

\footnotetext{
${ }^{8}$ DCMI Education Working Group: http://dublincore.org/groups/education/

${ }^{9}$ DC-Education AP:

http://dublincore.org/educationwiki/DC_2dEducation_20Application_20Profile

${ }^{10}$ GEM: Gateway to 21st Century Skills: http://www.thegateway.org/

${ }^{11}$ Education Network Australia: http://www.edna.edu.au/edna/go/resources/metadata

${ }^{12}$ Agricultural Metadata Element Set: http://www.fao.org/aims/
} 


\section{Application Profile for FAO’s Agricultural Learning Resources}

The needs analysis and the evaluation of existing standards resulted in an Agricultural Learning Resource AP (Ag-LR AP) which is created by taking elements from the following namespaces ${ }^{13}$ : Dublin Core Metadata Element Set (DCMES) ${ }^{14}$, IEEE LOM Metadata Set ${ }^{15}$ and AgMES ${ }^{16}$.

Twelve elements were taken from the DCMES namespace. Additional, elements from LOM are added to fulfill the task of fully describing a "learning resource". To identify the additional elements from LOM, it was necessary to evaluate the most commonly used LOM elements in other APs. The following elements were chosen from the educational category: "Intended End User Role”, "Context”, "Interactivity Level”, and "Typical Learning Time”. These elements, for example, indicate if a resource is intended for a learner or a trainer, if it is supposed to be used in school or training context and the foreseen average learning time.

One of the requirements of describing FAO learning resources was also to use standard terminologies such as FAO's multilingual agricultural thesaurus: the AGROVOC. AGROVOC is used by FAO and its member countries to describe agricultural resources. To allow consistent description of the learning resources in the Portal, it was important to provide the possibility to index resources with AGROVOC thesaurus. Therefore, elements from the AgMES, namely subject refinements and the possibility to explicitly indicate AGROVOC (or any other agricultural thesaurus) were included in the AP. This will allow FAO resources (learning and other types) to be searched simultaneously using the same keywords.

The resulting set of proposed elements as well as an example of a learning resource described and displayed using the AP is provided below.

\subsection{Overview of Proposed Elements}

An overview of the proposed elements to be included in the AP is provided in Table 1. The table also includes brief information about the controlled vocabularies used, the cardinality, and if it is mandatory or not. The details of each element and guidelines for adding content are available from the Agricultural Information Management Standards (AIMS) Web site ${ }^{17}$.

The AP is expressed using an XML Document-Type Definition (DTD). The DTD is used for validating exported XML metadata records. In the future, the same schema may be further expressed and exploited using Web Ontology Language (OWL). Nevertheless, to validate XML metadata records, a DTD is essential.

\footnotetext{
${ }^{13}$ XML Namespaces: http://www.w3.org/TR/REC-xml-names/

${ }^{14}$ Dublin Core Metadata Element Set (DCMES): http://dublincore.org/documents/2006/12/18/dces/

15 Standard for Information Technology --Education and Training Systems -- Learning Objects and Metadata: http://ltsc.ieee.org/wg12/

${ }^{16}$ Agricultural Metadata Element Set (AgMES): http://www.fao.org/aims/agmes_intro.jsp

${ }^{17}$ Agricultural Information Management Standards Web site - Learning Resources Metadata: http://www.fao.org/aims/ap applied.jsp
} 
Table 1. The elements of FAO Ag-LR AP with information about controlled vocabularies used, the cardinality and if it is required.

\begin{tabular}{|c|c|c|c|c|}
\hline Proposed Elements & $\begin{array}{l}\text { Name- } \\
\text { space }^{18}\end{array}$ & Controlled Vocabulary & $\begin{array}{l}\text { Require } \\
\text { ment } t^{19}\end{array}$ & $\begin{array}{l}\text { Cardi- } \\
\text { nality } 20\end{array}$ \\
\hline Title & DC & no & M & $\mathrm{R}$ \\
\hline Supplement Title & AGS & no & $\mathrm{O}$ & $\mathrm{R}$ \\
\hline Creator & DC & no & $\mathrm{O}$ & $\mathrm{R}$ \\
\hline Subject /FAO Categories & AGS & no & M & $\mathrm{R}$ \\
\hline Subject /Keywords & AGS & no & M & $\mathrm{R}$ \\
\hline Abstract & DCTERMS & no & $\mathrm{O}$ & $\mathrm{R}$ \\
\hline Notes & AGS & no & $\mathrm{O}$ & N-R \\
\hline Publisher & DC & no & M & N-R \\
\hline Date & DCTERMS & no & M & N-R \\
\hline Type & DC & yes: Type Vocabulary ${ }^{21}$ & M & $\mathrm{R}$ \\
\hline Format-Type & DC & yes: Format Vocabulary ${ }^{22}$ & M & $\mathrm{R}$ \\
\hline Aggregation Level & LOM & $\begin{array}{l}\text { yes: Aggregation Level } \\
\text { Vocabulary }{ }^{23}\end{array}$ & & \\
\hline Size & LOM & no & A & N-R \\
\hline Identifier & DC & no & M & N-R \\
\hline Language & DC & yes: Language Codes & M & N-R \\
\hline Relation & DC & $\begin{array}{l}\text { yes: "collections, } \\
\text { translations" }\end{array}$ & $\mathrm{O}$ & $\mathrm{R}$ \\
\hline Coverage & DCTERMS & yes: Official Country Names & $\mathrm{O}$ & $\mathrm{R}$ \\
\hline Rights & DC & no & $\mathrm{O}$ & $\mathrm{R}$ \\
\hline Cost & LOM & yes: "Yes, No" & $\mathrm{O}$ & N-R \\
\hline Intended End User Role & LOM & $\begin{array}{l}\text { yes: “Learner, Teacher, } \\
\text { Manager” }\end{array}$ & $\mathrm{O}$ & $\mathrm{R}$ \\
\hline Context & LOM & $\begin{array}{l}\text { yes: "School, Higher } \\
\text { Education, Training, other" }\end{array}$ & $\mathrm{O}$ & $\mathrm{R}$ \\
\hline Interactivity Level & $\mathrm{LOM}$ & $\begin{array}{l}\text { yes: "very low, low, medium, } \\
\text { high, very high" }\end{array}$ & $\mathrm{O}$ & N- R \\
\hline Typical Learning Time & LOM & - & $\mathrm{O}$ & $\mathrm{N}-\mathrm{R}$ \\
\hline
\end{tabular}

${ }^{18}$ Namespaces: Dublin Core (DC), Dublin Core Terms (DCTERMS), Agricultural Metadata Element Set (AGS), Learning Object Metadata (LOM)

${ }^{19}$ Mandatory (M) / Optional (O) / Automatic (A)

${ }^{20}$ Repeatable (R) / Not-Repeatable (N-R)

${ }^{21}$ Type vocabulary: Training/Learning Resource, Training/Learning Support Material, Portal, Best Practice, Case Study, Policy Brief, Reference Material

${ }^{22}$ Format vocabulary: Electronic Document, Paper only Document, Slides, Website, CD-Rom / DVD, Audio, Video

${ }^{23}$ Aggregation Level Vocabulary: 1: raw media data or fragments, 2: lesson, 3: course, 4: e.g. a set of courses that lead to a certificate 


\subsection{Example of a FAO Resource Described Using Ag-LR AP}

Figure 1 shows an example of a FAO learning resource described and displayed using FAO Ag-LR AP.

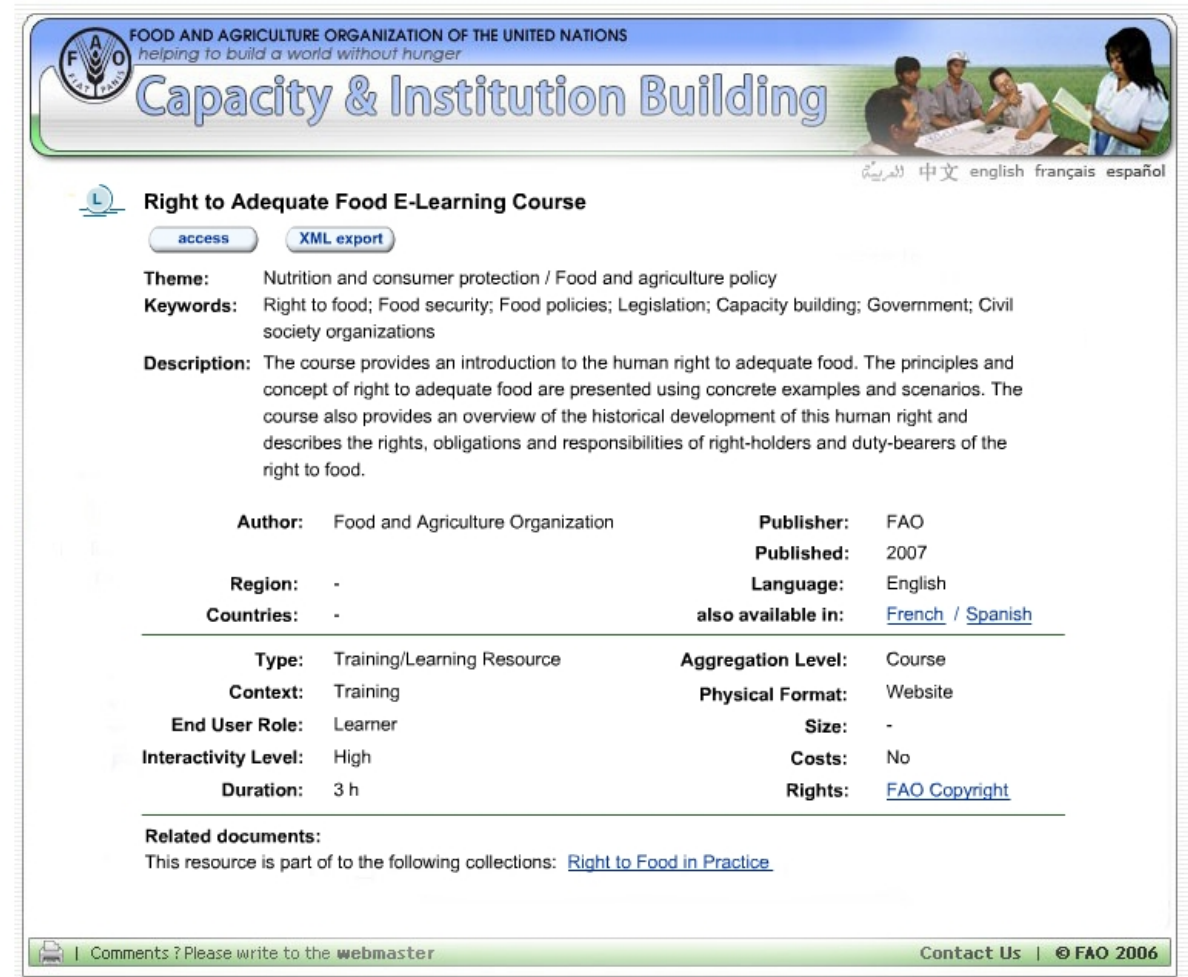

Fig. 1. Example for a record describing an online module on the Right to Food.

\subsection{Mapping to LOM}

To enable interoperability with other repositories, such as the CGIAR LOR, a mapping of the elements from the Ag-LR AP to their LOM equivalents has to be done. Table 2 provides an overview of the elements and their equivalents as well as possible interoperability issues.

Next to the elements which can be mapped, there are some LOM elements which can be generated automatically for the XML export, e.g. elements from the metametadata category. 
Table 2. Elements of FAO Ag-LR AP and their LOM equivalents with reference to possible issues for mapping and exchange of records.

\begin{tabular}{|c|c|c|}
\hline Element AP (Namespaces) & LOM equivalent $(\mathrm{No})^{24}$ & Possible Issues \\
\hline Title (DC) & Title (1.2) & \\
\hline Supplement Title (AGS) & - & \\
\hline Creator (DC) & Contribute (2.3) / Role: Author & AP does not use vCard \\
\hline $\begin{array}{l}\text { Subject /FAO Categories } \\
\text { (AGS) }\end{array}$ & Classification (9) & \\
\hline $\begin{array}{l}\text { Subject /FAO Keywords } \\
\text { (AGS) }\end{array}$ & Keyword (1.5) & \\
\hline Abstract (DCTERM) & Description (1.4) & \\
\hline Notes (AGS) & - & \\
\hline Publisher (DC) & $\begin{array}{l}\text { Contribute (2.3) / Role: } \\
\text { Publisher }\end{array}$ & AP does not use vCard \\
\hline Date (DCTERMS) & $\begin{array}{l}\text { Contribute (2.3) / Role: } \\
\text { Publisher / Date (2.3.3) }\end{array}$ & \\
\hline Type (DC) & Learning Resources Type (5.2) & customized vocabulary \\
\hline Format-Type (DC) & Format (4.1) & customized vocabulary \\
\hline Aggregation Level (LOM) & Aggregation Level (1.8) & \\
\hline Size (LOM) & Size (4.2) & \\
\hline Identifier (DC) & Identifier (1.1) & \\
\hline Language (DC) & Language (1.3) & \\
\hline Relation (DC) & Relation (7) & \\
\hline Coverage (DCTERMS) & Coverage (1.6) & \\
\hline Rights (LOM) & $\begin{array}{l}\text { Copyright and Other } \\
\text { Restrictions (6.2) / }\end{array}$ & \\
\hline Cost (LOM) & Costs (6.1) & \\
\hline $\begin{array}{l}\text { Intended End User Role } \\
\text { (LOM) }\end{array}$ & Intended End User Role (5.5) & \\
\hline Context (LOM) & Context (5.6) & \\
\hline Interactivity Level (LOM) & Interactivity Level (5.3) & \\
\hline Typical Learning Time (LOM) & Typical Learning Time (5.9) & \\
\hline
\end{tabular}

\section{Conclusion}

The AP presented above meets the needs of FAO's Capacity and Institution Building Portal which is currently under development. However, more importantly, it is also extendable to the wider agricultural community and its learning resources through the inclusion of AgMES elements (which are used to describe many of the learning resources such as "case studies", "training materials" etc.) and agriculture

${ }^{24}$ (No): indicates the number of the LOM element. 
specific schemes such as AGROVOC. The use of standard metadata schemas and XML export functionality ensures that information can be shared with other webbased repositories. This interoperability allows for various value-added services.

1. It allows for exchange of information across applications using varying systems that in turn are using different schemas and different encoding guidelines.

2. The generic Ag-LR AP adheres to the unqualified DC metadata set which is used as a common harvesting format by the Open Archives Initiative ${ }^{25}$ (OAI) Community. The Ag-LR AP facilitates exposure of the agricultural content to a wider audience by making the metadata harvestable and available.

3. A recent study [7] concluded that more and more resources are being retrospectively added to the Web. Based on this study, availability of good quality metadata allows for retrieval of the original resource, regardless of its actual location on the Web.

\section{References}

1. 59/250. Triennial comprehensive policy review of operational activities for development of the United Nations system [59/250]. United Nations General Assembly: Resolution adopted by the General Assembly [on the report of the Second Committee (A/59/488/Add.1)] (2005). http://daccessdds.un.org/doc/UNDOC/GEN/N04/491/26/PDF/N0449126.pdf

2. Friesen, N.: Connecting Collections: An overview of approaches (2006) http://www.cancore.ca/protocols_en.html

3. Friesen, N.: Editorial - A Gentle Introduction to Technical E-learning Standards. In: Canadian Journal of Learning and Technology. Volume 30(3) (2004) http://www.cjlt.ca/content/vol30.3/normeditorial.html

4. ISO/IEC JTC1 SC36: Working Draft for ISO/IEC 19788-2 - Metadata for Learning Resources - Part 2: Data Elements (2005)

5. ISO/IEC JTC1 SC36: Final Report on the "International LOM Survey" (2004) http://jtc1sc36.org/doc/36N0871.pdf

6. Tzikopoulos, N. Manouselis, R. Vuorikari: An Overview of Learning Object Repositories. In: Northrup, P. (ed): Learning Objects for Instruction: Design and Evaluation. Idea Group Publishing, 2007 (accepted)

7. Salokhe, G., Weinheimer, J., Bovo, M.G., Agrimi, M: Structured Metadata for Direct Resource Location: A Case Study (2003). http://www.siderean.com/dc2003/404_Paper84color.pdf

${ }^{25}$ Open Archives Initiative: http://www.openarchives.org/ 